\title{
Studies on the Effect of Trypan Blue in the Pregnant Armadillo, Dasypus novemcinctus '
}

\author{
VERGIL H. FERM AND ALLAN R. BEAUDOIN \\ Department of Pathology, Dartmouth Medical School, Hanover, \\ New Hampshire, and the Department of Anatomy, University \\ of Michigan Medical School, Ann Arbor, Michigan
}

\begin{abstract}
Evilence is presented that the hemochorial placenta of the ninebanded armadillo, Dasypus novemcinctus, is permeable to trypan blue when this dye is injected subcutaneously into the mother during the post-implantation period. This permeability appea:s to be related to a time-dependent active process or is associated with the maturation of the fetal reticulo-endothelial system. Spectrophotometric analysis of serum proteins revealed alterations in the dye-injected mothers as well as in thalidomide-treated animals as compared to untreated controls. While it is difficult at present to estimate the stage of pregnancy under teratogenic study, it is felt that this unusual experimental animal warrants further study with other teratogenic agents.
\end{abstract}

The relationship between the teratogenicity of trypan blue and the permeability of the mammalian placenta to this dis. azo dye continues to be a perplexing prob$\mathrm{l} \in \mathrm{m}$. In experimental teratogenesis in rodents (Gillman et al., '4t8; Hamburgh, '52; Ferm, '58) it is clear that, at least during the later stages of gestation, the placenta is impermeable to this compound, the endoderm of the yolk sac placenta absorbing great quantities of the dye and presumably preventing it from reaching the fetus. Few studies have been made on the permeability of diverse types of mammalian placentas to this classic teratogen. Wislocki ('20) injected trypan blue into pregnant cats near term and noted that the dye did not cross the placenta to reach the fetus. The chorioni: epithelium of the labyrinth stored the dye in the form of granules. Whether it has teratogenic activity in the cat has not been recorded nor has the permeability of the placenta during early stages of gestation been studied. In the rabbit, however, tryjoan blue does cross into the blastocyst fluid during the critical stages of embryogenesis (Ferm, '56) and thus its teratogenic effect in this species may be explained by a direct toxic effect on the embryo.

Serum protein changes associated with the teratogenicity of tryjan blue have been reported in the pregnant rabbit (Langman and van Drunen, '59; B aaudoin and Ferm, '61). These changes consisted primarily of significant elevations of the alpha and beta globulin fractions. Alterations in protein composition of the blastocyst fluid was found to mimic those of the maternal serum (Hommes, '59; Beaudoin and Ferm, '61).

In the rat, Yamada ('59) and Paoletti et al. ('62) reported an "abnormal" protein in the serum of male rats treated with trypan blue. Dijkstra and Gillman ('60) made similar observations in some, but not all samples of sera they examined. Recently, it has been shown that fetal rat sera from fetuses of mothers treated with trypan blue had significantly lower concentrations of alpha-1 globulin, beta globulin, and albumin than fetal sera from fetuses of untreated mothers. (Beaudoin and Kahkonen, '63).

We have had the opportunity to investigate the effect of trypan blue on gestation in the pregnant armadillo, Dasypus novemcinctus mexicanus. This species breeds late in the summer months and implantation of the blastocyst is delayed until late November or early December. Shortly after implantation, the single blastocyst regularly divides into four embryonic buds, each bud giving rise to separate, but presumably genetically identical embryos. The armadillo also possesses a hemochorial villous placenta strikingly similar to man and a yolk sac placenta

1 Supported by USPHS grants GM-10210 and HD00400 . 
which does not remain vascularized (Patterson, '13). Therefore, it is of interest to record the results of experiments designed to study the effect of trypan blue on identical mammalian quadruplets, the relative permeability of a hemochorial villous placenta to this compound, and the related serum protein changes following injection of the dye.

\section{MATERIALS AND METHODS}

Female armadillos were purchased from a supplier in Texas and received in November. There is no simple and accurate method to determine the time of implantation, the stage of pregnancy, or even the event of pregnancy. The animals were injected subcutaneously between the rows of scutes on the dorsal surface with trypan blue (National Aniline) made up as a $2 \%$ solution in saline. Prior to injection, this solution was passed through a Seitz filter for sterilization, and no infections resulted. Eight animals were injected in the period. from November 30 through January 10. At the end of the experimental period, which lasted from 10 to 26 days, the animals were etherized and, in most cases, cardiac blood was drawn. Fetuses were recovered from two of these animals and definite evidence of fetal resorption was found in an additional animal. The uterus was opened and, in the event of pregnancy, the fetuses and fetal membranes examined for gross evidence of trypan blue staining. Representative samples of maternal liver, kidney, ovary, and uterus, as well as fetal membranes and fetal tissues, if present, were fixed in Bouin's fluid and paraffin sectioned for histological study.

Cardiac blood was allowed to clot and then centrifuged to collect the serum. The serum was frozen at $-40^{\circ} \mathrm{C}$ until electrophoretic studies were done. Paper electrophoresis was carried out in a Spinco cell using Spinco B-2 buffer (Veronal at $\mathrm{pH}$ $8.6 ; 0.075$ ionic strength). The paper strips were run for 17 hours at $3.5 \mathrm{ma}$. The strips were subsequently stained with bromphenol blue and their density was measured in a Spinco Analytrol (recording densitometer) to determine the relative concentration of each component. Total protein was measured with a Bausch and Lomb Serum Protein Meter.

Two different sets of control animals were used. One group consisted of four animals which had received no treatment and which were sacrificed during the course of the experimental period. Another group had received thalidomide (100 $\mathrm{mgm} /$ day for 10 days ) and was then sacrificed (table 1). Thalidomide is an apparent teratogen in the armadillo and exerts a marked embryocidal effect (Marin-Padilla and Benirschke, '63).

TABLE 1

Summary of number and pregnancy status in armadillos treated with trypan blue and thalidomide

\begin{tabular}{|c|c|c|}
\hline Animal no. & Treatment & Pregnancy status \\
\hline 572 & None & $\begin{array}{c}\text { Control - pregnant } \\
4-30 \mathrm{~mm} \text { fetuses }\end{array}$ \\
\hline 578 & None & $\begin{array}{l}\text { Control - pregnant } \\
4-37 \mathrm{~mm} \text { fetuses }\end{array}$ \\
\hline 596 & None & Control non-pregnant \\
\hline 597 & None & Control non-pregnant \\
\hline 522 & Trypan blue & Non-pregnant \\
\hline 523 & Trypan blue & Non-pregnant \\
\hline 527 & Trypan blue & Non-pregnant \\
\hline 583 & Trypan blue & Corpus luteum - no embryos \\
\hline 586 & Trypan blue & Corpus luteum - no embryos \\
\hline 528 & Trypan blue & Resorbing embryos \\
\hline 585 & Trypan blue & Pregnant: $4-22 \mathrm{~mm}$ fetuses \\
\hline 526 & Trypan blue & Pregnant: $4-40 \mathrm{~mm}$ fetuses \\
\hline 563 & Thalidomide & Non-pregnant \\
\hline 562 & Thalidomide & Corpus luteum - no embryos \\
\hline 564 & Thalidomide & Corpus luteum - no embryos \\
\hline 565 & Thalidomide & Pregnant: $4-9 \mathrm{~mm}$ embryos \\
\hline
\end{tabular}

Trypan blue - a single injection of $120 \mathrm{mgm}$ - then sacrificed in ten days, except for animal no, 526 which received $120 \mathrm{mgm}$ of dye 26 days prior to sacrifice

Thalidomide - $100 \mathrm{mgm}$ daily for ten days - then sacrificed. 


\section{RESUL:.:S}

It is difficult to estimate the relative embryocidal effect of trypan blue on the armadillo fetus from th.ese data. In those animals possessing ovarian corpora lutea at the time of sacrifice. we have assumed that ovulation has taken place and that either a prolonged delay in implantation of the blastocyst has occirred or the blastocyst had died prior to implantation. For lack of better knowledge in this matter we have combined those animals possessing corpora lutea only, and those with definite evidence of fetal resorp ion (table 2). The effect on embryonic siurvival of capture, handling, and transpostation by air over long distances are also difficult to evaluate in this species. Nevertheless, two litters of armadillos survived 10 and 26 days of exposure to trypan blue respectively (table 1) and none of the members of these litters had succumbed tc the effects of the dye nor did they appear to be adversely affected by the dye treatment.

The placenta of the nine-banded armadillo is permeable to trypan blue. Grossly the amnion and fetuses were stained a distinct blue. Trypan blue granules were noted diffusely throughout the placenta with a more marked concentration in the syncytial layer of the trophoblast. That animal (no. 526) which was sacrificed 26 days after trypan blue injection, showed considerable staining of the syncytiotrophoblast and dye granules could be found within the Hofbauer cells of the chorionic villi (fig. 3) and umbilical cords of all four fetuses.

Histological evidence of the dye was found in the fetal liver (fig. 4) and in connective tissue cells throughout the fetal body (figs. 5, 6). There was no apparent pattern to its distribution within the fetus. Longer exposure to trypan blue (no. 526) caused greater staining of both placental and fetal tissues. In contrast to the marked concentration of the dye within the maternal kidney (fig. 1), no dye was detectable within the fetal kidney. There was no apparent gross or microscopic difference in the amount or distribution of trypan blue within the fetal tissue or their placentas in the four members of a single litter. One pregnant armadillo, not included in these data, was injected in a similar manner with trypan blue and sacrificed in 72 hours. There was only a faint localization of dye in the chorionic epithelium of the placenta and no dye could be detected within the fetal tissues proper.

No congenital malformations were noted in the two litters surviving trypan blue treatment although it is quite probable that the introduction of the dye occurred later than the critical stages of embryogenesis, as demonstrated by the size of the fetuses recovered at the time of sacrifice (table 1 ).

Analysis of the maternal serum (table 2) revealed six distinct protein bands following paper electrophoresis in all serum

TABLE 2

Total protein and protein fraction concentration in serum of control and trypan blate and thalidomide treated armadillos

\begin{tabular}{|c|c|c|c|c|c|c|c|c|}
\hline \multirow{2}{*}{ Treatment } & \multirow{2}{*}{$\begin{array}{l}\text { No. of } \\
\text { animals }\end{array}$} & \multirow{2}{*}{$\begin{array}{c}\text { Total } \\
\text { protein } 1\end{array}$} & \multicolumn{5}{|c|}{ Globulin 1} & \multirow{2}{*}{ Albumin ${ }^{1}$} \\
\hline & & & Gamma & Beta-2 & Beta-1 & Alpha-2 & Alpha-1 & \\
\hline \multicolumn{9}{|l|}{ Control } \\
\hline Non-pregnant & 2 & 6.35 & 1.17 & 0.75 & 0.78 & 0.92 & 1.14 & 1.59 \\
\hline Resorb-CL & 0 & - & - & - & - & - & - & - \\
\hline Pregnant & 2 & 6.90 & 0.85 & 0.66 & 0.84 & 1.06 & 1.19 & 2.30 \\
\hline \multicolumn{9}{|l|}{ Trypan blue } \\
\hline Non-pregnant & $\mathbf{3}$ & 5.55 & 1.32 & $0.50^{2}$ & 0.73 & 0.69 & 0.75 & 1.89 \\
\hline Resorb-CL & 3 & 4.67 & 0.87 & $0.27^{3}$ & 0.73 & 0.59 & 0.79 & 1.42 \\
\hline Pregnant & 2 & 6.40 & 1.02 & 0.40 & 0.80 & 0.62 & 1.06 & 2.50 \\
\hline \multicolumn{9}{|l|}{ Thalidomide } \\
\hline Non-pregnant & 1 & 5.15 & 0.96 & 0.68 & 0.85 & 0.85 & 1.07 & 0.74 \\
\hline Resorb-CL & 2 & 6.50 & 1.20 & 0.64 & 0.61 & 1.02 & 1.13 & 1.90 \\
\hline Pregnant & 1 & 6.10 & 0.92 & 0.56 & 0.66 & 0.87 & 0.96 & 2.13 \\
\hline
\end{tabular}

i Concentration expressed is grams per $100 \mathrm{ml}$.

2 Value for only one sample.

3 Average of only two samplies. 
samples except three from animals treated with trypan blue. In these serum samples, only five protein bands were discernible; the sixth band, in the beta globulin region, was lacking. The identification of the protein bands was based on a comparison of the present results with those obtained following electrophoresis of rat serum. By comparing the $\mathrm{Rf}$ values of armadillo serum and rat serum, it was concluded that armadillo serum has five bands representing globulins; one gamma, two beta, and two alpha: the remaining band represents albumin. Because of the limited number of animals available for this study, a definitive interpretation of the results is not possible. A comparison of control animals with the trypan blue and thalidomide treated animals shows that the total protein was lowered in both experimental groups, as was the concentration of alpha globulins. The concentration of beta globulins was lowered in all trypan blue treated animals and in the pregnant thalidomide treated animals but remained relatively unchanged in the non-pregnant thalidomide group. Gamma globulin and albumin appear unaffected by either treatment. The significance of these observations, if any, is presently not known.

\section{DISCUSSION}

The teratogenicity of specific compounds is known to vary with the species in which the compound is used. The degree and specificity of the teratogenic effect of trypan blue has been shown to differ among various strains of rats (Gunberg, '58), and rabbits (Harm, '54; Ferm, '56). Thalidomide is a most significant teratogen in this respect, its greatest teratogenic effect to date being in man, while it exerts much less or no such effects in other species (Cohlan, '63). Thus, the effect of specific teratogenic compounds may be explained by the genetic factors of the embryo and/or parents. In addition to this, however, the problem of placental permeability as it relates to the expression of teratogenesis must be considered. Since mammalian placentation varies considerably in structure and functional adaptation (Mossman, '37) it is highly probable that the factor of placental permeability may well influence the availability of a potentially teratogenic compound to the mammalian embryo.

The yolk sac placenta, characteristic of rodents, concentrates trypan blue in considerable quantities and is the presumed barrier preventing the dye from reaching the fetus (Ferm and Beaudoin, '61; Barber and Geer, '64). It is of interest that, although the armadillo possesses a yolk sac placenta, it does not remain vascularized and does not concentrate trypan blue.

The appearance of trypan blue in the fetal tissue appears to be in the cells of the reticulo-endothelial system. Since the larger fetuses (no. 526) showed the greater fetal concentration of trypan blue, it may indicate that maturation of the reticuloendothelial system is a necessary prerequisite for concentration of trypan blue within the fetal tissues in this species. Further studies on this point will be of considerable interest.

No consistent explanation of the serum protein changes associated with trypan blue teratogenicity in the rodent has yet appeared. In this limited series of observations in the armadillo, similar findings are suggested, these being almost as marked in the thalidomide controls as in the trypan blue series. Armadillos which are fed thalidomide for a ten day experimental period similar to this show a marked anorexia and weight loss (Marin-Padilla and Benirschke, '63). This may be severe enough to help explain the serum protein changes. What association these serum protein changes have with those induced by trypan blue treatment, however, is not apparent from these data, but it is important to note that in this study trypan blue produced no anorexia, weight loss, or lethargy.

The lack of congenital malformations in the armadillo fetuses of these series is not surprising in view of the fact that the fetuses were presumed to be past the critical stages of embryogenesis when treatment was begun. It would appear that since trypan blue persists in the serum in large quantities for long periods of time, future experiments with this teratogen in this species should utilize earlier injections of trypan blue, possibly during the period 
of delayed implantation. This particular teratogen then would be present during the critical stages of embryogenesis. The marked sensitivity of the armadillo blastocyst to thalidomide as clemonstrated by the lethal effect of this compound upon the implanting blastocyst (Marin-Padilla, '64) must be kept in mind. A comparison of the effect of other known teratogens in this species would be of extreme interest.

\section{ACKNOWLEIIGMENTS}

We wish to acknowledge the assistance of Dr. Miguel Marin-Padilla, for allowing us to bleed those armatillos under thalidomide treatment. We are also indebted to Mr. J. Sawdy for his exacting care of the armadillos under capt.vity.

\section{LITERATURE CITED}

Barber, A. N., and J. C. Cieer 1964 Studies on the teratogenic properties of trypan blue and its components in mice. J. Embryol. Exp. Morph., 12: 1-14.

Beaudoin, A. R., and V. H. Ferm 1961 The effect of disazo dyes on protein metabolism in the pregnant rabbit. J. Exp. Zool., 147: 219225.

Beaudoin, A. R., and D. Kahkonen 1963 The effect of trypan blue on the serum proteins of the fetal rat. Anat. Rec., 147: 387-395.

Cohlan, S. Q. 1963 Teratogenic agents and congenital malformations. J. Ped., 63: 650-659.

Dijkstra, J., and J. Gillm in 1960 Trypan blue concentration and protiein composition in sera of rats injected repeatedly with trypan blue in relation to reticulosis and reticulo-sarcoma. $\mathbf{S}$. Afr. J. Med. Sci., 25: 1.19-131.

Ferm, V. H. 1956 Perneability of the rabbit blastocyst to trypan blu e. Anat. Rec., 125: 745759.

1958 Teratogeric effects of trypan blue on hamster embryos. J. Embryol. Exp. Morph., 6: 284-287.
Ferm, V. H., and A. R. Beaudoin 1961 Absorptive phenomena in the explanted yolk sac placenta of the rat. Anat. Rec., 137: 87-92.

Gillman, J., C. Gilbert, T. Gillman and I. Spence 1948 A preliminary report on hydrocephalus, spina bifida, and other congenital anomalies in the rat produced by trypan blue. S. Afr. J. Med., Sci., 13: 47-90.

Gunberg, D. L. 1958 Variations in the teratogenic effects of trypan blue administered to pregnant rats of different strain and substrain origin. Anat. Rec., 130: 310 (abst.).

Hamburgh, M. 1952 Malformations in mouse embryos induced by trypan blue. Nature, Lond., 169: 27.

Harm, H. 1954 Der Einfluss von Trypanblau auf die Nachkommenschaft trägtiger kaninchen. Z. Naturforsch., 9b: 536-540.

Hommes, O. R. 1959 Trypan blue in the rabbit. Acta Morph. Neerl. Scand., 2: 28-37.

Langman, J., and H. van Drunen 1959 The effect of trypan blue upon maternal protein metabolism and embryonic development. Anat. Rec., 133: 513-526.

Marin-Padilla, M. 1964 Thalidomide injury to an implanted armadillo blastocyst. Anat. Rec., 149: 359-362.

Marin-Padilla, M., and K. Benirschke 1963 Thalidomide induced alterations in the blastocyst and placenta of the armadillo, Dasypus novemcinctus mexicanus, including a choriocarcinoma. Amer. J. Path., 43: 999-1016.

Mossman, H. W. 1937 Comparative morphogenesis of the fetal membranes and accessory uterine structures. Carn. Contrib, to Emb., 26: 129-246.

Paoletti, C., G. Riou and R. Truhaut 1962 Electrophoretic pattern of plasma proteins in rats treated with trypan blue and ethionine. Nature, 193: 784-785.

Patterson, J. T. 1913 Polyembryonic development in Tatusia novemcincta. J. Morph., 24 : 559-682.

Wislocki, G. B. 1920 Experimental studies on on fetal absorption. Carn. Contrib to Emb., 11: $45-60$.

Yamada, T. 1959 Abnormal serum protein observed in trypan blue treated rats. Proc. Soc. Exp. Biol. Med., 101: 566-568. 
PLATE 1

EXPLANATION OF FIGURES

1 Maternal kidney of armadillo receiving $6.0 \mathrm{~cm}^{3} 2 \%$ trypan blue subcutaneously 26 days prior to sacrifice. Kidneys were grossly stained a deep blue and dye granules are distributed primarily in the proximal tubules. Eosin stain only. $\times 263$.

2 Maternal liver from same animal as fig. 1. Dye granules appear in reticulo-endothelial cells of liver sinusoids. Eosin. $\times 263$.

3 Dye granules in trophoblast cell of placenta. Distribution of dye granules appears to be quite diffuse and uniform and restricted primarily to the synctiotrophoblast. Eosin. $\times 263$.

4 Fetal liver from same pregnancy showing dye granules in liver sinusoidal cells. Liver also shows normal hematopoietic activity. Fetal crown-rump length of $40 \mathrm{~mm}$. Eosin. $\times 263$.

5-6 Trypan blue granules in connective issue cells of dorsal body wall from same fetus. Eosin. $\times 263$. 

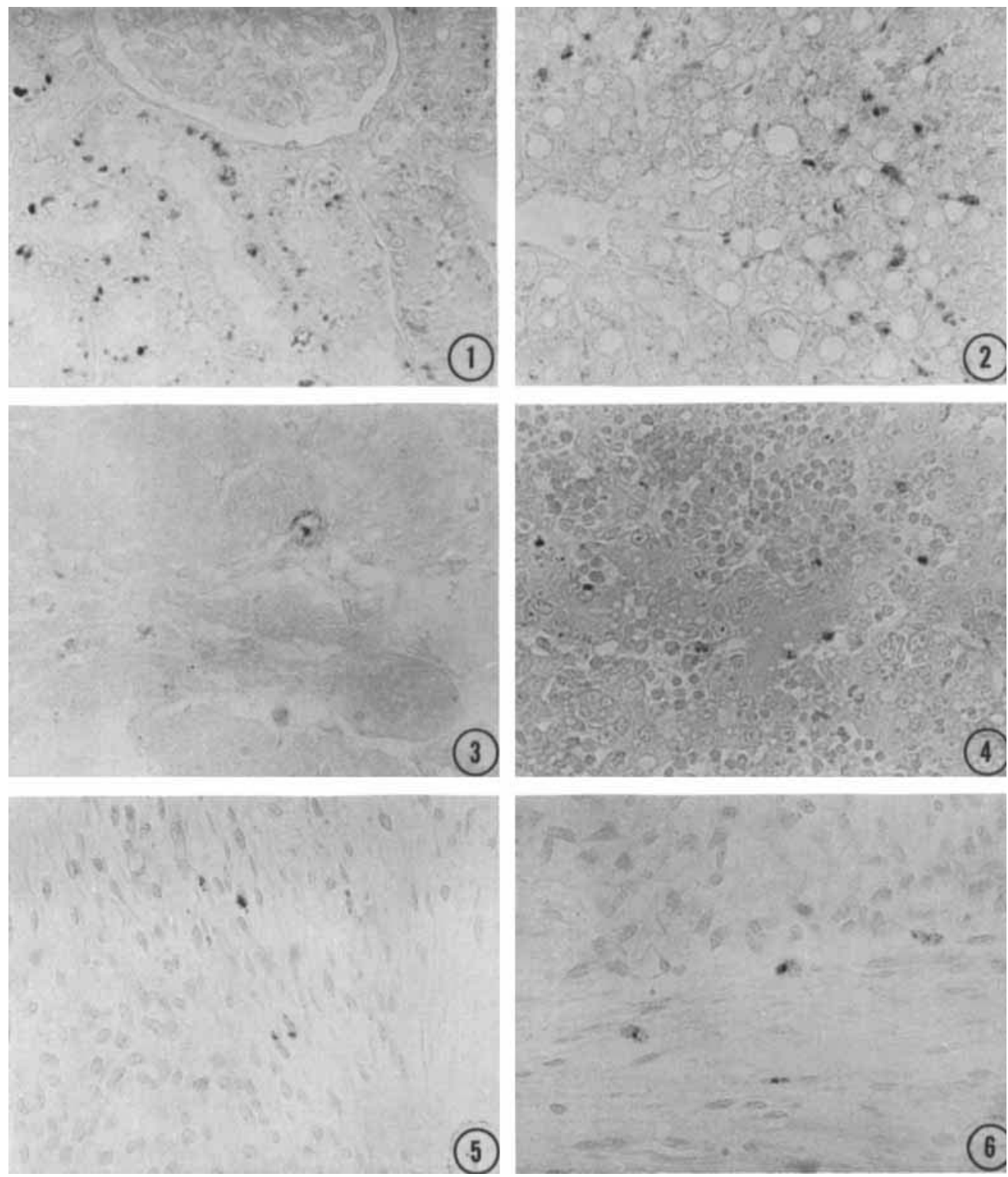